\title{
EFFICIENT LIGHT VEHICLE PCU TO MEET ROTA 2030 TARGETS
}

\author{
Matheus Ferreira, Rafael Bruno, Bruno Fineto, Heitor Chaves \\ MAHLE Metal Leve S.A. \\ E-mails: matheus.ferreira@br.mahle.com, rafael.bruno@br.mahle.com, \\ bruno.fineto@br.mahle.com, heitor.chaves@br.mahle.com
}

\begin{abstract}
The contribution of the Power Cell Unit (PCU) to the overall engine efficiency through friction reduction has been widely discussed along the past years.

The recent launch of the new governmental legislation named ROTA 2030 as replacement for INOVAR-AUTO has established new challenging targets of fuel consumption reduction, making the need for new modern technologies even more prominent. The adoption of downsized engines sometimes combined with turbocharger technology has shown to be the choice of car manufacturers to comply with the new rules. As a result, PCU components will have to contribute to fuel consumption reduction, besides being more demanded in terms of performance and robustness.

Car manufactures that do not comply with the new targets by 2022 will be in cost disadvantage in a very competitive market.

Using the experience gained on INOVAR-AUTO, a high feature PCU was selected to attend this new market demand. Results of numerical simulation and fuel consumption in a dynamometer bench tests are presented to support the discussions.
\end{abstract}

\section{INTRODUCTION}

ROTA 2030 was officially launched in November 2018, replacing INOVAR-AUTO program, which was focused on incentives for R\&D only for car manufactures. The new governmental legislation program creates incentives for the automotive industry (car and automotive parts manufactures) by granting tax reduction to companies that invest on research and development (R\&D) [1].

The main goals of the ROTA 2030 are to boost the investments in energy-efficient resources, improve the structural performance of vehicles, incentive the autonomous vehicle technology in the national market, produce new technologies aligned with global trends, promote biofuels and alternative propulsions, increase industry productivity and integrate the Brazilian automotive industry into global level [2]. 
The objective of this paper is to present design optimization strategies for pistons, pins, piston rings and bearings aiming to directly decrease fuel consumption through friction reduction and also aiming to enable the use of other technologies able to improve engine efficiency, for instance compression rate increase.

\section{CURRENT MARKET OVERVIEW}

In order to have a better understanding of the challenges introduced by the fuel efficiency targets defined in the ROTA 2030, it was carried out a market analysis evaluating the car manufacturer's status in 2022, year when the tax reduction will start being applied as defined in the legislation.

Starting from the most recent results published in the PBEV (Brazilian program of vehicle labeling) combined with strategic information gathered with customers, partners and consultants, it was estimated sales, fuel consumption and off cycle discounts of the main vehicles that are thought to be in the market by 2022 including hybrid and electric ones.

As result of this market evaluation, the plot presented in figure 1 was created compiling the applications and their positions compared to the habilitation curves for light vehicles, Sport Utility Vehicles (SUVs) and light commercial vehicles

The analysis of this graph indicate that the majority of the applications will be out of target and, therefore, car manufacturers will have to apply solutions to reduce fuel consumption to avoid fines and to qualify to the targets defined by the ROTA2030.

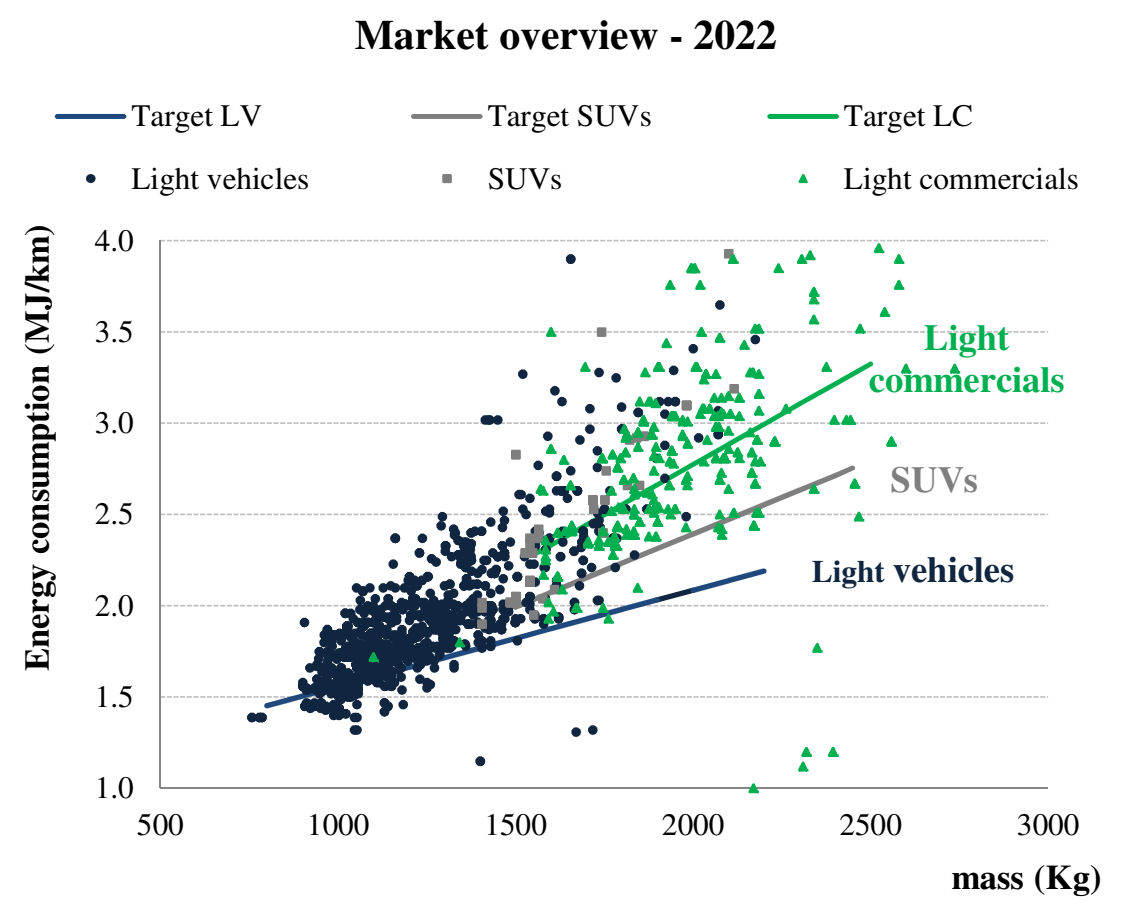

Figure 1: MAHLE market overview by 2022 
Figure 2 shows an example of the above methodology applied to one high volume car manufacturer (intentionally named as "A" in this paper) demonstrating the need to reduce fuel consumption in $2 \%$ for light vehicles and $5 \%$ for light commercials vehicles to avoid fines. Besides this case, other cases were analyzed showing the same trend.

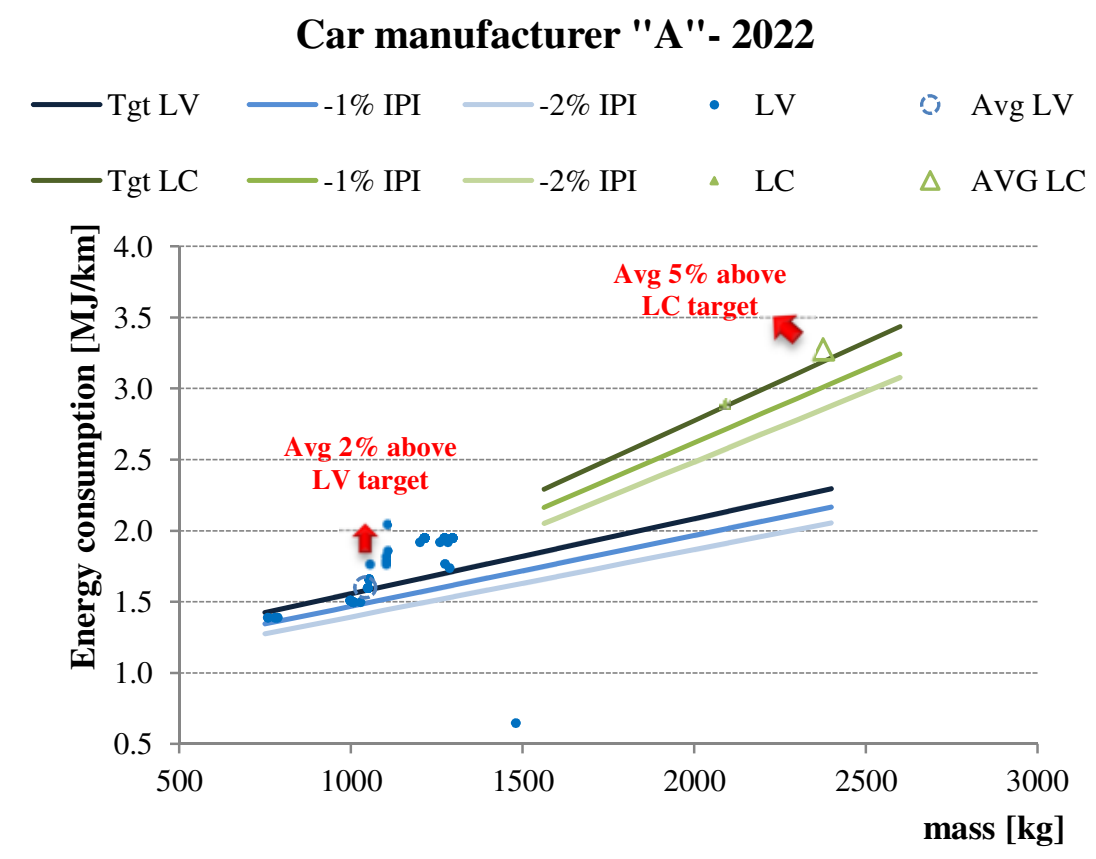

Figure 2: Projection of portfolio efficiency for car manufacturer "A" in 2022

\section{COMPONENT DESIGN OPTIMIZATION}

A series of advanced resources including computer simulations, tribological bench tests and engine dynamometer cells were used to analyze the impact of PCU components and its attributes on friction. Combining the knowledge gathered from all these resources, a friction tool was developed as a fast assessment tool to predict the impact of PCU optimization on fuel consumption (Figure 3). 


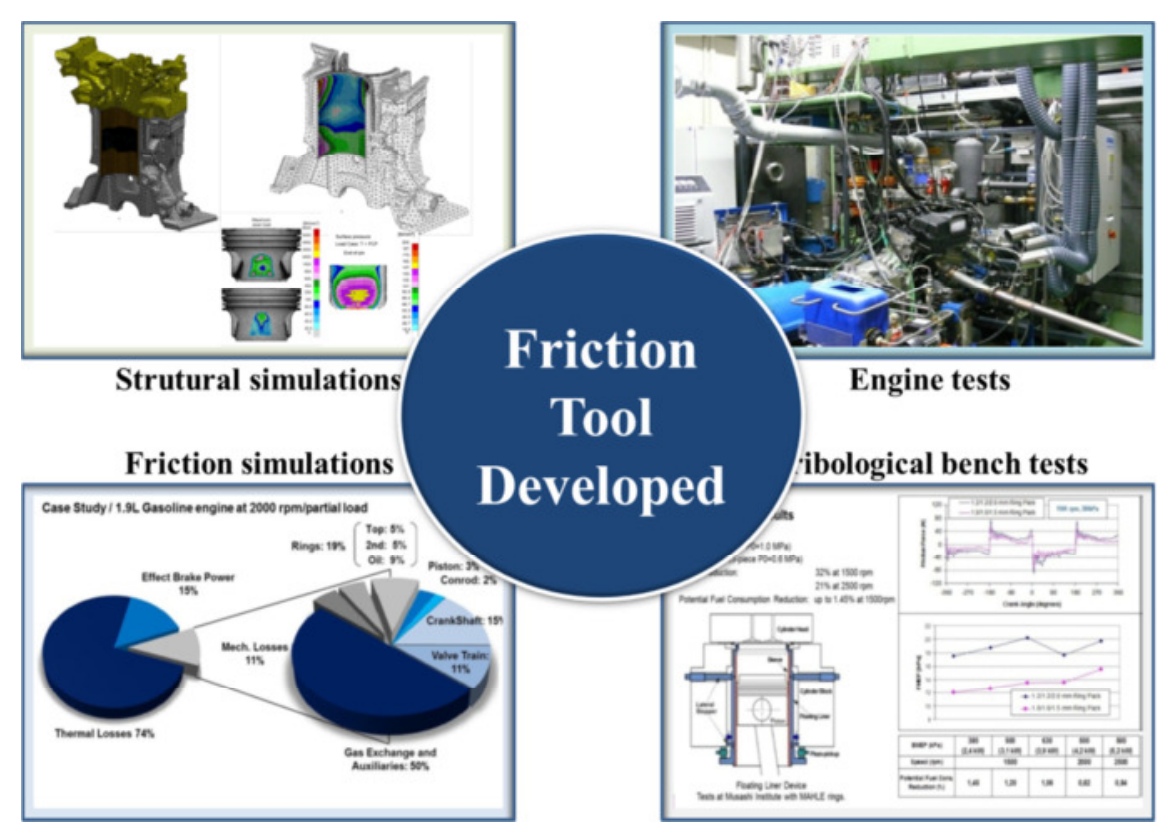

Figure 3: Developed friction tool.

Predictions from this tool have already been compared to real measurements in the past showing good accuracy therefore being adopted in this work as basis to develop and select PCU optimizations that contribute to improve energy efficiency, especially looking to driving cycles such as FTP75 and Highway.

A critical aspect to optimize PCU components is to demonstrate the benefits in real engine tests. For that purpose, it was developed a special test procedure allowing improved accuracy in fuel consumption measurement.

An active dynamometer cell as showed in figure 4 containing the state of the art equipment to monitor and control the engine and the boundary conditions was used for these evaluations. Among these equipment, the most important to ensure precise measurements are the Coriolis fuel flow meter, the torque flange and the PID (Proportional Integrative Derivative) valves to control the temperature of fuel, intake air, coolant and lubricant oil.

As shown in figure 4, the steady state conditions that compose the Specific Fuel Consumption (SFC) mapping are chosen based on the time residence in the FTP75 cycle. After the data acquisition, a statistical analysis is carried out to ensure accuracy of $\pm 0.4 \%$ in fuel consumption measurements. 


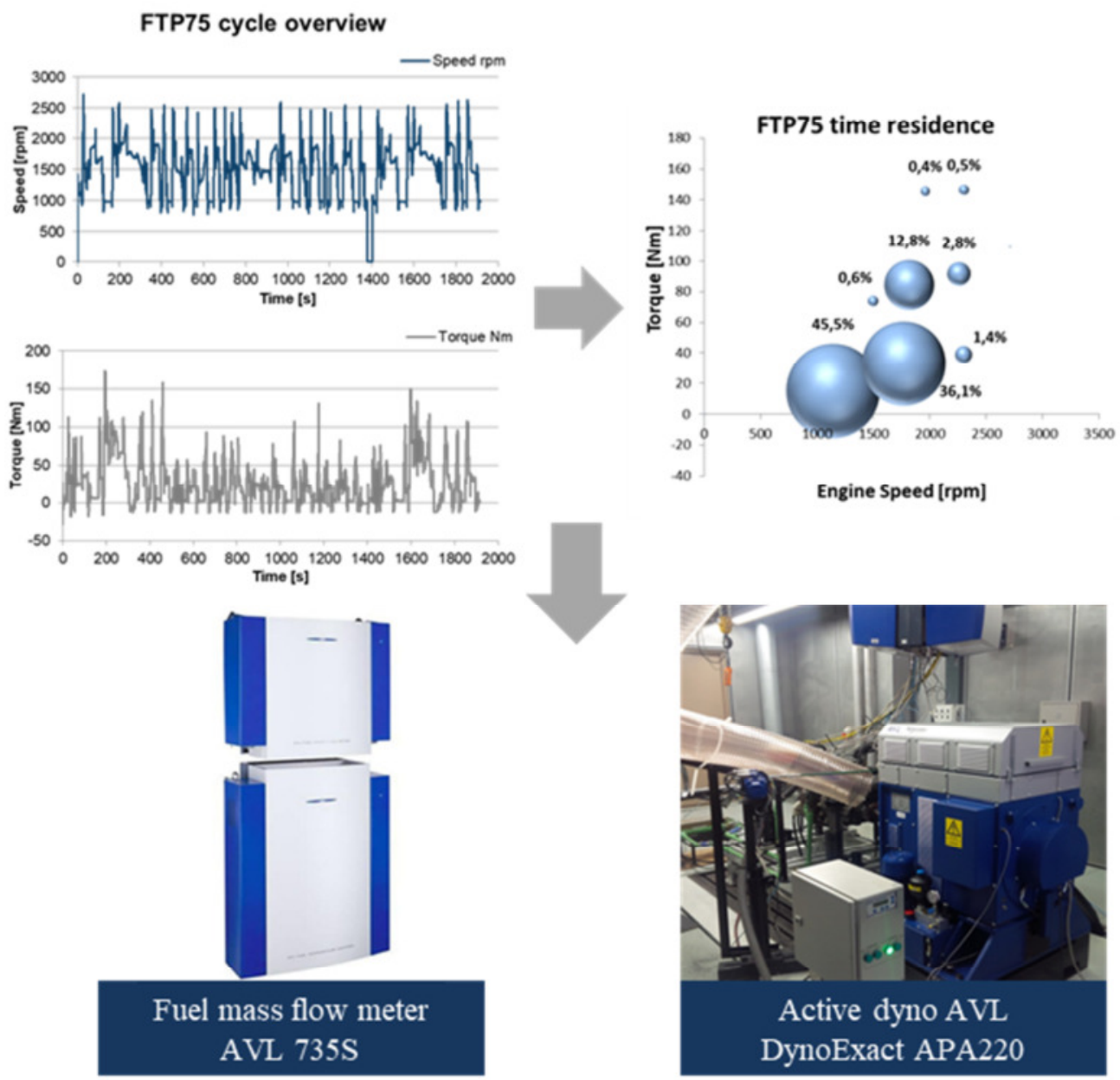

Figure 4: Experimental setup to high accuracy SFC measurement

\section{OPTIMIZED PCU}

The PCU optimization strategies present in this work are divided in two categories: friction and thermal efficiency. Two cases were selected as demonstration of influence of PCU parameters for each category regarding fuel consumption reduction.

\section{FRICTION}

The PCU components (figure 5) can be optimized to reduce friction [3,4] consequently reducing fuel consumption. Parameters that affect friction for each component are described on Table 1. 


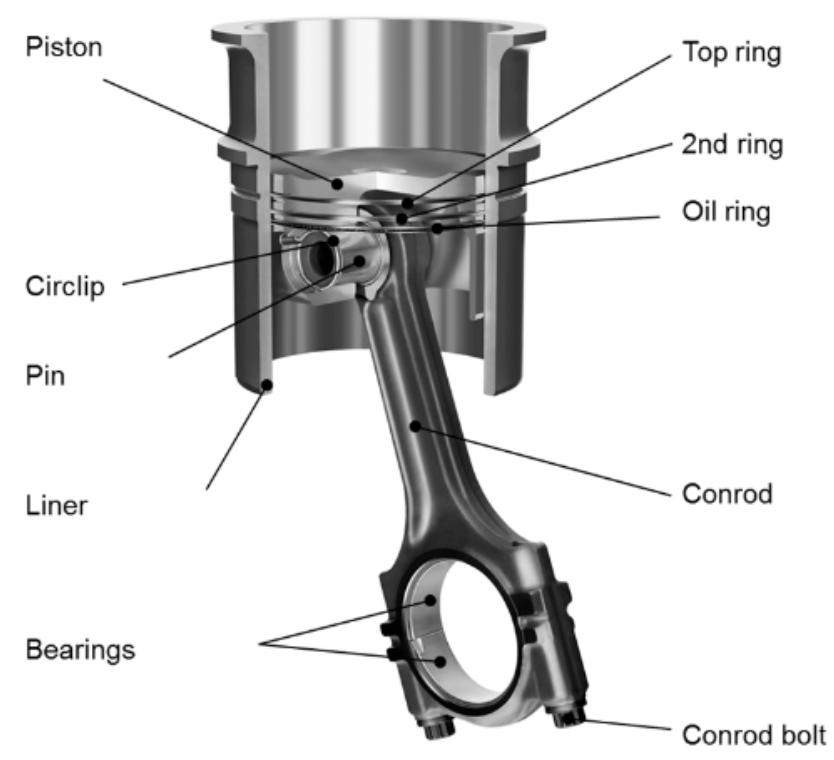

Figure 5: Typical PCU components

Table 1: Product parameters for potential friction reduction.

\begin{tabular}{|c|l|}
\hline PCU Product: & Friction Reduction by: \\
\hline \multirow{4}{*}{ Piston } & Installation clearance \\
\cline { 2 - 2 } & Skirt Roughness \\
\cline { 2 - 2 } & Skirt Area / Profile \\
\cline { 2 - 2 } & Weight Reduction \\
\hline \multirow{3}{*}{ Pin } & DLC Coating (bushingless) \\
\cline { 2 - 2 } & Weight Reduction \\
\hline \multirow{4}{*}{ Ring Pack } & Rings axial width reduction \\
\cline { 2 - 2 } & Rings tension reduction \\
\cline { 2 - 2 } & Materials / coatings with low Friction Coefficient \\
\hline \multirow{5}{*}{ Bearings } & Working clearance reduction \\
\cline { 2 - 2 } & Width and diameter reduction \\
\cline { 2 - 2 } & Improved surface roughness \\
\cline { 2 - 2 } & Profiles, material and coating selection \\
\hline
\end{tabular}

As mentioned before in the market analysis the majority of car manufacturers will have to work either on engine optimization or vehicle mass reduction (besides the use of off cycles alternatives) to ensure the attendance of ROTA 2030 limits.

PCU features can be an important contributor to reduce the distance from current fuel consumption levels to the required ones. Piston clearance, pin coating, rings tangential force, bearings width and diameter are only few examples.

The main PCU technology is described below along with the dynamometer bench test results. 


\subsection{Piston and Pin}

Piston clearance increase is one of the most influencing parameter on friction reduction. Besides that, piston weight, skirt profile and roughness play an important role.

By increasing the running clearance, Noise, Vibration and Harshness (NVH) might become challenging, especially on lighter designs such as EVOLITE®, which was the selected design for the first case. NVH was extensively analyzed using the NVH chamber available at the Technology Center in Jundiaí - SP and a balance between the optimal clearance and acceptable NVH levels was studied during the EVOLITE® piston development.

This design allow for skirt optimization (reduced area) and weight reduction without compromising stiffness and durability. Figure 6 show the comparison of EVOTEC $®$ versus EVOLITE® design, evidencing thinner walls for the second one which is the responsible for the weight reduction.
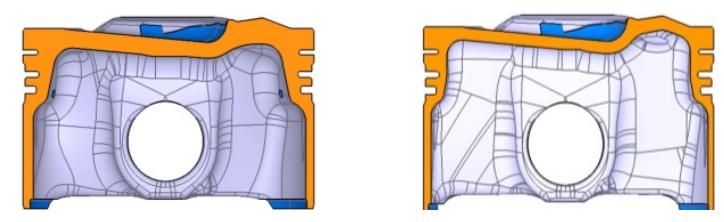

Figure 6: EVOTEC® vs. EVOLITE®

In the particular case selected in this work, the EVOLITE® piston associated with the optimized pin design resulted in $10 \%$ weight reduction compared to the series piston, as showed on figure 7 .

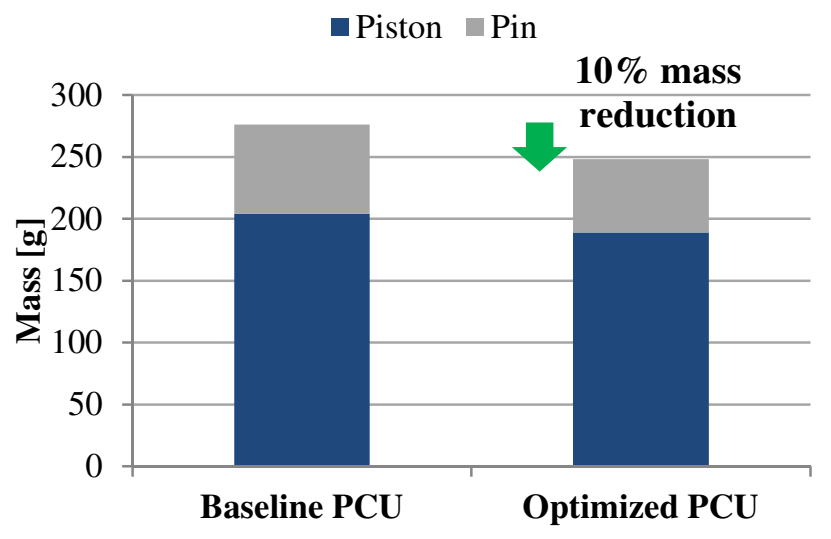

Figure 7: PCU mass reduction

\subsection{Piston rings}

The piston rings have an important role on providing good blow-by and lube oil consumption levels [5], as well as ensuring adequate heat flow from the piston to the cylinder.

High efficiency engines usually require a low friction ring pack concept [6], which can be primarily translated to lower tension rings. The challenge lies on finding the best design 
compromise targeting the minimum tangential load $(\mathrm{Ft})$ level but still keeping both the lube oil consumption and blow-by within the target levels.

For the particular engine used for this demonstration, the Upper Compression Rings (UCR) was optimized by reducing the tangential load by $19 \%$. Besides that it was possible to propose a cost reduction measure, replacing nitride stainless steel by carbon steel. Neither of the design changes has affected the ring performance or durability.

For the Lower Compression Ring (LCR) the tangential load was reduced by $48 \%$.

Oil Control Ring (OCR) presents the highest potential for friction reduction once it has the higher tangential force within the ring pack. However reducing Ft for OCR may have a detrimental effect on LOC. In order to prevent this negative side effect, rail dimensions were reduced (axial width and radial thickness) to keep the ring conformability and the unitary pressure (P0) within the acceptable range.

Ring conformability is an important ring performance parameter because it expresses the ability of the ring to radially conform itself to eventual bore distortions caused by thermalmechanical loads.

OCR unitary pressure is also a key parameter to determine ring performance, once it is an indication of the OCR oil scraping efficiency. For maintaining an acceptable level of P0, Ft reduction has been partially compensated by rail axial width reduction.

Table 2 shows the optimizations applied on piston rings for the specific naturally aspirated engine used on this demonstration to reduce fuel consumption.

Table 2: Piston rings optimization.

\begin{tabular}{|c|c|c|c|}
\hline PCU Product & Design Feature & Baseline & Optimized \\
\hline \multirow{4}{*}{$\begin{array}{l}\text { Upper } \\
\text { Compression } \\
\text { Ring } \\
\text { (UCR) }\end{array}$} & Axial Width (mm) & 1.0 & $\leftarrow$ \\
\hline & Tangential Force $(\mathrm{N})$ & 6.2 & $-19 \%$ \\
\hline & Base Material & $\begin{array}{c}\text { Nitrided } \\
\text { Stainless Steel }\end{array}$ & Carbon Steel \\
\hline & Running Face Coating & Uncoated & $\mathrm{CrN}$ - PVD \\
\hline \multirow{3}{*}{$\begin{array}{l}\text { Lower } \\
\text { Compression } \\
\text { Ring } \\
\text { (LCR) }\end{array}$} & Axial Width (mm) & 1.2 & $\leftarrow$ \\
\hline & Tangential Force $(\mathrm{N})$ & 9.7 & $-48 \%$ \\
\hline & Base Material & Cast Iron & $\leftarrow$ \\
\hline \multirow{6}{*}{$\begin{array}{l}\text { Oil Control } \\
\text { Ring } \\
\text { (OCR) }\end{array}$} & Axial Width (mm) & 2.0 & $\leftarrow$ \\
\hline & Rail Axial Width (mm) & 0.46 & 0.35 \\
\hline & Tangential Force $(\mathrm{N})$ & 34.3 & $-53 \%$ \\
\hline & Unitary Pressure (MPa) & 1.00 & $-40 \%$ \\
\hline & Base Material & $\begin{array}{c}\text { Nitrided } \\
\text { Stainless Steel }\end{array}$ & $\leftarrow$ \\
\hline & Running Face Coating & $\begin{array}{l}\text { Uncoated } \\
\text { (Nitrided) }\end{array}$ & $\leftarrow$ \\
\hline
\end{tabular}


The total tangential load of the ring pack was reduced by $48 \%$ as presented in Figure 8 . This new level of tension is considered aggressive for Brazilian market.

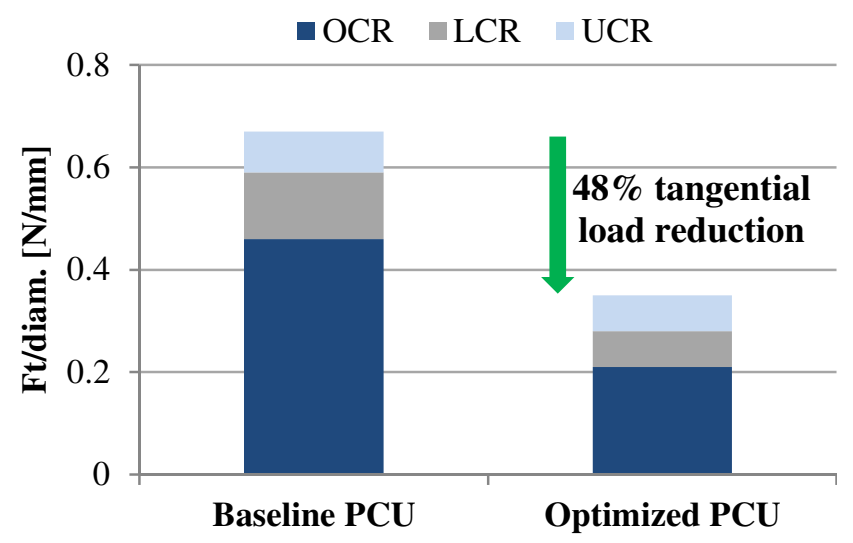

Figure 8: Tangential load reduction applied in a naturally aspirated engine

\subsection{Test results for the first case: friction reduction}

To demonstrate the effect of friction reduction on fuel consumption, a short SFC measurement was performed using a 1.0L, 3 cylinders, SI, naturally aspirated, PFI engine. For this specific engine, the proposed optimized PCU included lighter piston pin (18\% mass reduction), EVOLITE® pistons and low friction ring pack (as presented in Table 2 and Figure 8).

In this engine test, only the most relevant steady state conditions in the FTP75 cycle were measured. Lube Oil Consumption and blow-by were verified and are presented in figure 9, showing values according to the target for this application. The SFC mapping results are presented in figure 10 .
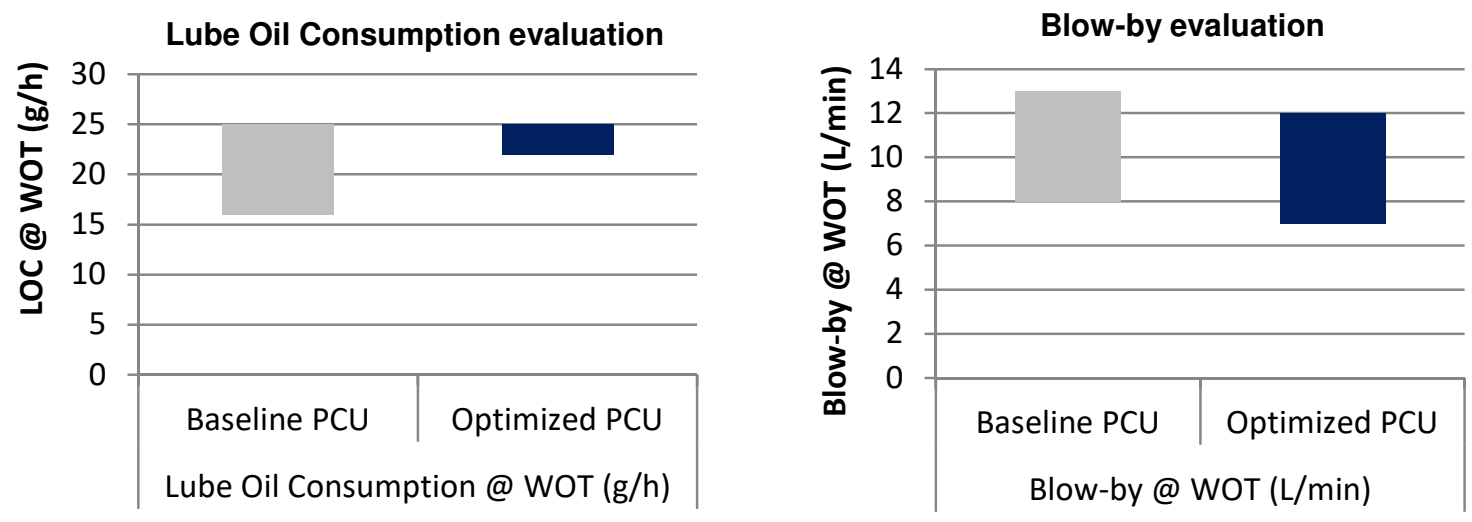

Figure 9: Lube oil consumption and blow-by evaluations. 


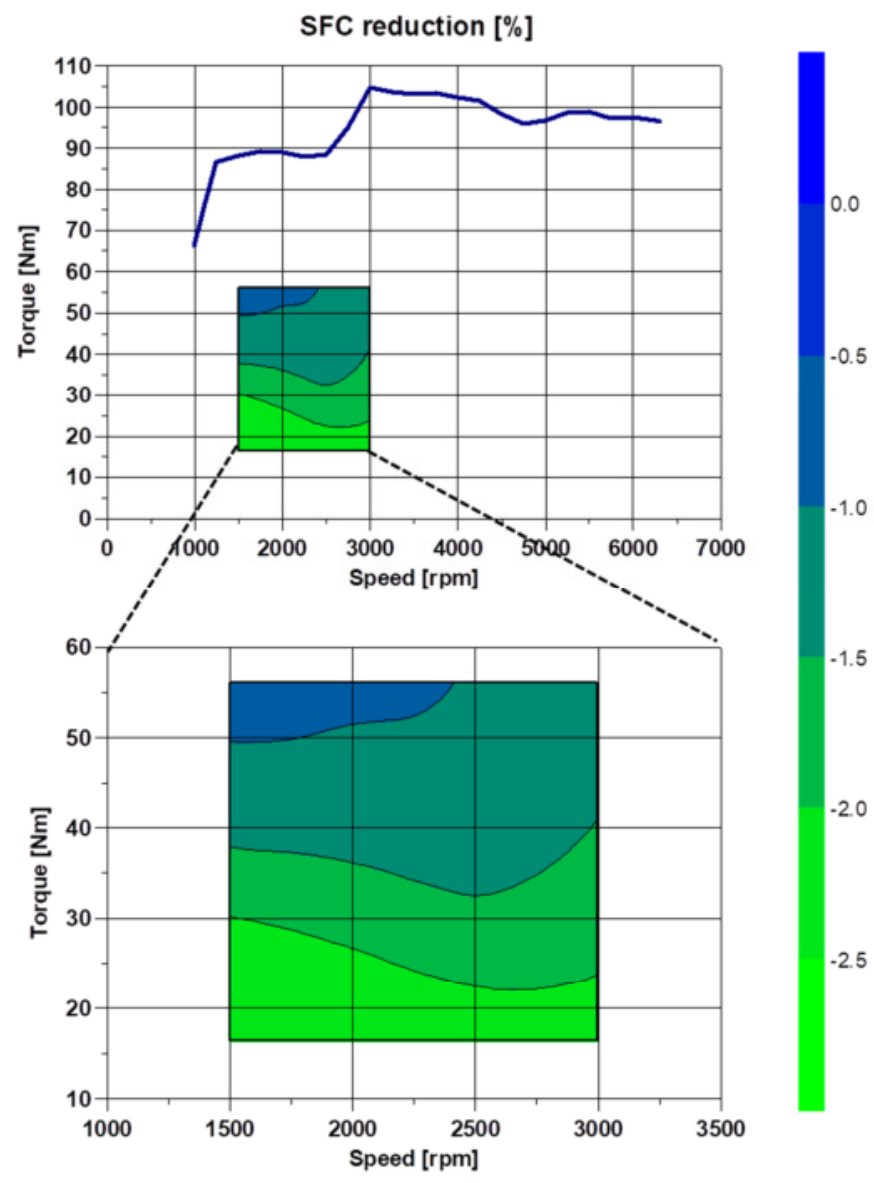

Figure 10: SFC reduction as result of application of friction optimized PCU

The selected mapping area corresponds to $74 \%$ of the FTP75 time residence. The maximum SFC reduction in this area was $2.5 \%$ and the average, $1.5 \%$. This data was used to simulate the fuel consumption in the FTP75 cycle and resulted on an estimated fuel saving of $1.8 \%$.

\section{THERMAL EFFICIENCY}

Another target brought by the ROTA 2030 is to improve the efficiency of flex fuel engines using ethanol, or, in other words, to improve the gasoline/ethanol parity. For that purpose, one of the most accessible solutions is to increase the compression ratio (CR) of the engines.

As shown in figure 11, increasing the compression ratio directly increases the theoretical thermal efficiency of the engine [7]. However, the octane number of the available commercial gasoline, the occurrence of knocking at high load conditions and the increase of peak combustion pressure (PCP) bring challenges to implement this concept. 


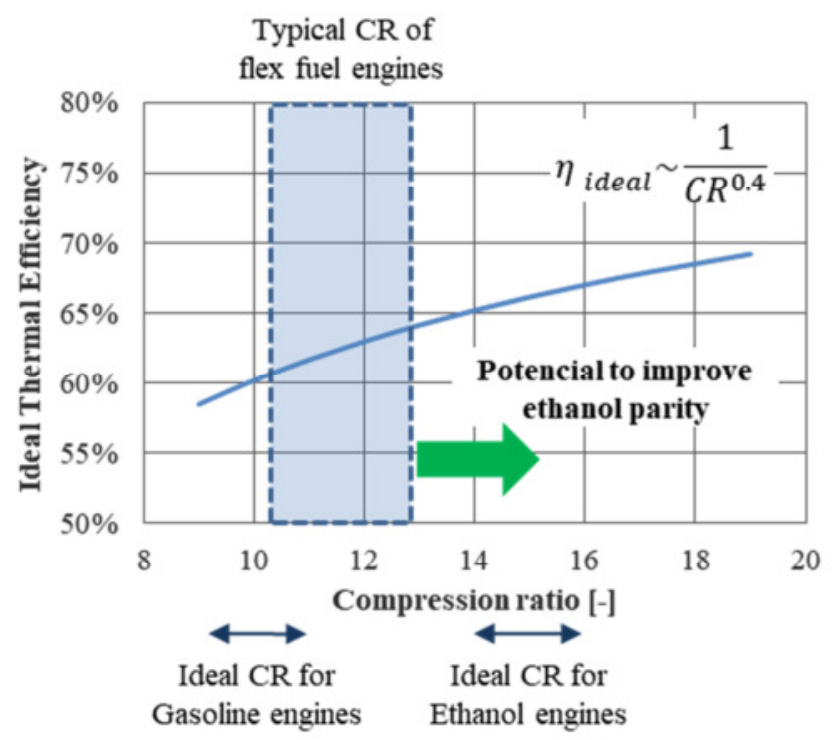

Figure 11: Influence of compression ratio on thermal efficiency

One of the biggest challenges to design and optimize flex fuel engines is finding the ideal compression ratio that promotes fuel efficiency and durability with both gasoline and ethanol. Considering the current $\mathrm{CR}$ of the existing flex fuel engines in the Brazilian market, engine efficiency using ethanol would benefit greatly from a higher CR due to the superior octane number of this fuel [8]. However, this change could jeopardize the engine operation with gasoline due to knocking occurrence.

To cope with this demand, EVOTEC Salt Core (SC) piston is available which incorporates a cooling gallery which in this case was able to decrease the maximum piston temperature up to $20^{\circ} \mathrm{C}$, as show in the simulation results presented in figure 12 . 


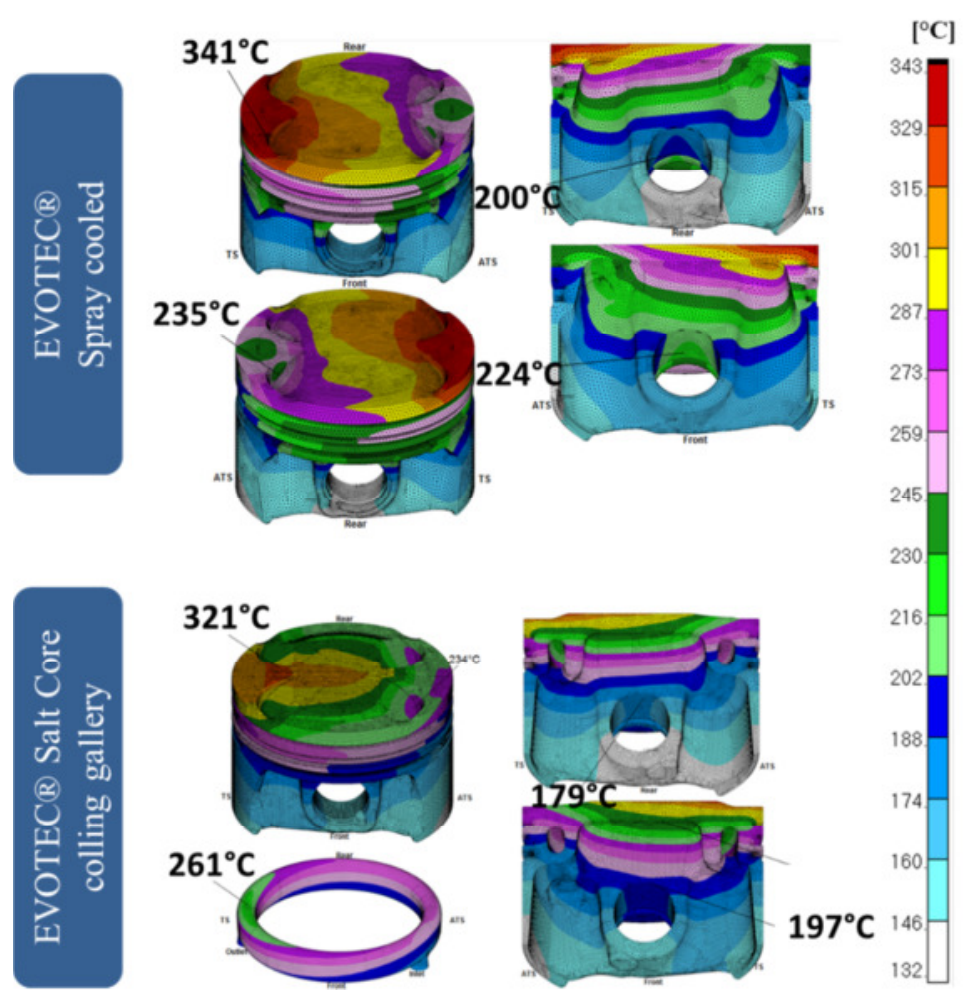

Figure 12: Piston temperature simulation for 1.0L, turbocharged, SI engine

This temperature reduction is beneficial not only because it increases the piston life in downsized high-loaded engines, but also because the lower temperature on the piston crown reduces the occurrence of hot spots in the combustion chamber that would otherwise initiate knocking events. Therefore, this technology enables the compression ratio increase aiming to increase the engine efficiency with ethanol without compromising the engine operation and durability when using gasoline.

As seeing in figure 13, for engines with even higher mechanical and thermal loads, the EVOTEC Salt Core piston can also contain a ring carrier (RC) to improve the groove protection and maintain the piston durability in engines with higher compression ratio and/or peak cylinder pressure.
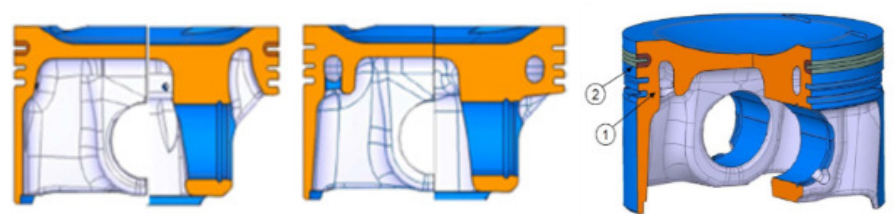

Figure 13: EVOTEC RC® vs. EVOTEC SC® vs. EVOTEC RSC®

\subsection{Test results for second case: thermal efficiency}

To demonstrate the potential of increasing fuel efficiency with ethanol by increasing the compression ratio, an engine test was performed using a modern $1.0 \mathrm{~L}$, turbocharged, direct 
injection, spark ignition, flex fuel engine. In this project, the current piston design was improved to an EVOTEC Salt Core ${ }^{\circledR}$ and the CR of the engine was increased in $10 \%$.

The fuel consumption of the engine was mapped with the baseline components and calibration. After that, the pistons were replaced and the engine calibration was adjusted looking to optimize the spark advance for the new compression ratio, but still looking at the PCP and knocking limits previously defined.

The plot presented in figure 14 shows up to $3 \%$ SFC reduction using ethanol comparing the results of the baseline engine with the optimized proposal with $10 \%$ increase on CR. Due to the reduced piston temperature, the engine operation with gasoline was not spoiled even maintaining the original knocking and PCP limits.

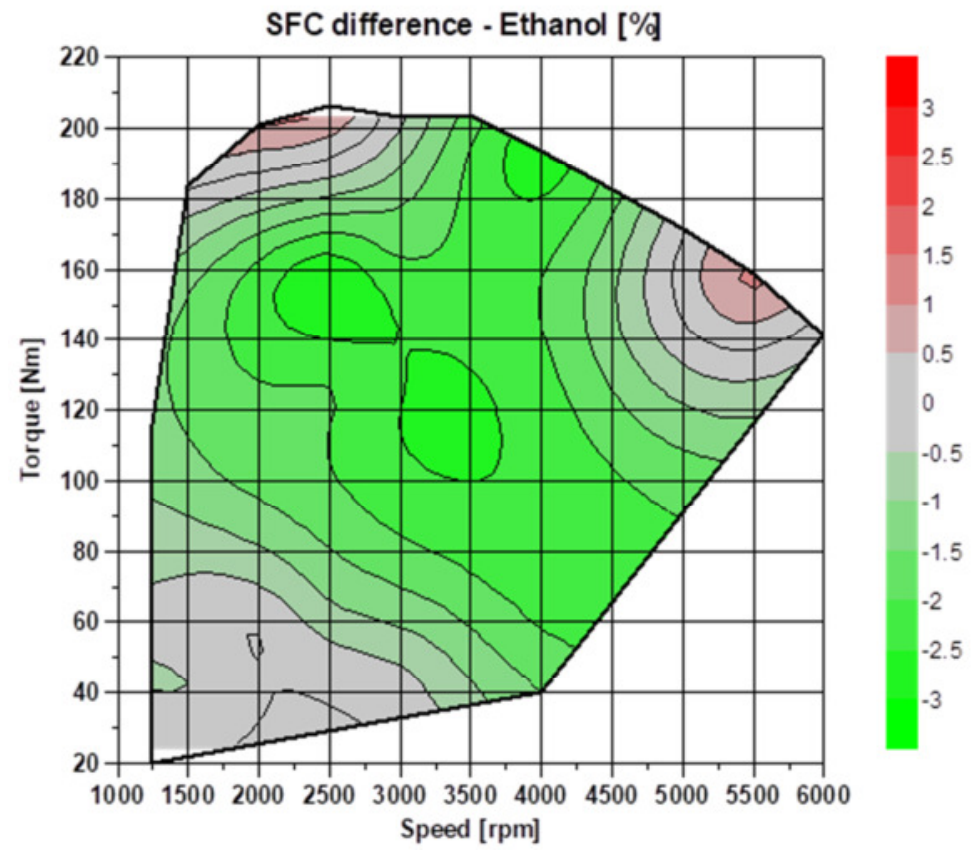

Figure 14: SFC comparison, baseline vs proposal

The SFC map shown in figure 14 was used to simulate the fuel consumption in the FTP75 and highway cycles. This simulation indicated an improvement of around $1 \%$ and an improvement of $1 \%$ in the gasoline/ethanol parity in the combined cycle (NBR7024).

\section{POTENTIAL IMPROVEMENTS BEYOND 2022}

The ROTA 2030 program is divided in three main phases. The first milestone is 2022, when the car manufactures will be eligible or not to tax discounts using current or improved engine technologies.

Usually the development time for a new engine or even for an improved one takes three years or more. Therefore, the opportunity to do major modifications to the existing engines before 2022 are reduced. After 2022 the phase two of the program will take place and is seeing as the highest potential for new developments, along with phase three. 
PCU technologies that were not considered in this first phase for efficiency increase can be explored during subsequent phases for further optimization of the engine.

Some examples such as EVOLITE Salt Core pistons combined with DLC pins and low tension rings pack are technologies to be further explored. Bearings can also bring significant contribution to friction reduction, especially hydrodynamic friction. A brief description of potential technologies to be used in the near future is available below.

\section{Pistons}

The technologies described above can be summed to create an EVOLITE® RSC (Ring Salt Core) piston which will combine both the light weight design with the benefit of reduced working temperatures coming from the use of a cooling gallery. The use of a DLC coated pin, which is already available in the market, is also recommended to reduce friction and increase efficiency.

Rings

Reduced tangential forces have shown to be a well-known trend when looking for friction reduction. However the lower limits are yet to be discovered and must keep good control of LOC and blow-by. Further Ft reduction is only possible if suitable honing parameters along with controlled bore distortion are available.

The major benefit of reduced tangential forces comes from OCR usually. In order to keep LOC under acceptable limits, a new rail profile coated with PVD or DLC is available to maintain P0 at experienced levels.

\section{Bearings}

A newly developed optimized oil groove for the main bearings has shown increase of up to $20 \%$ on oil pump pressure when compared to standard design. This means that the oil pump can be redesigned to reduce its contribution on mechanical losses. Other features like eccentricity, edge relief, locating nick design and clearance can be redesigned to reduce hydrodynamic friction and side leakage even further.

\section{CONCLUSION}

The ROTA 2030 program has brought the target of energetic efficiency to a more challenging level when compared to INOVAR-AUTO. Some car manufacturers are able to meet the new targets with the use of modern technologies like direct injection and turbocharged engines.

However, currently these high cost technologies do not represent the reality of most engines in Brazil. The majority of high volume engines will be out of target by 2022 and will have to evolve or even be replaced by new engines in order to keep competitiveness. 
The high feature PCU's demonstrated in this paper presented up to $2.5 \%$ fuel consumption reduction when focusing on improving friction reduction and $3 \%$ fuel consumption reduction when focusing on improving thermal efficiency.

Therefore the use of such PCU's can be determinant to assist on achieving the new limits established by ROTA 2030 especially in borderline cases.

Further improvements can be done for the second and third phases of the program - thought to take place after 2022 - by combining the technologies described before or using new ones recently developed.

\section{REFERENCES}

[1] Law 13755/18, Brazil. Union Official Diary 11/12/2018. Available at: https://www.jusbrasil.com.br/diarios/DOU/2018/12/11 (Accessed on 13/05/2019)

[2] Sturgeon, T., L. L. Chagas and J. Barnes. Rota 2030: Updating Brazil's Automotive Industrial Policy to Meet the Challenges of Global Value Chains and the New Digital Economy. World Bank Working Paper, Washington DC, 2017.

[3] Tomanik, E.; Ferrarese, A. "Low Friction Ring Pack For Gasoline Engines" - paper ASME ICEF2006-1566 (2006).

[4] Mordente, P. and Bruno, R.A.; "Top Ring Technology to Low Fuel Consumption Flex Fueled Engines" SAE paper 2009-36-0128 (2009).

[5] Ferrarese, A.; Rovai, F.; "Oil Ring Design Influence on Lube Oil Consumption of SI Engines”, ASME paper ICEF2004-868.

[6] Pereira, M; Bruno, R. A.; "Low Width Oil Control Rings for SI Engines" SAE paper 2007-01-2830 (2007).

[7] Heywood, J. B.; "Internal combustion engine fundamentals", McGraw-Hill series in mechanical engineering (1988).

[8] Gomes, P. C. F.; Franieck, E. K.; Mendes, C. F., Baeta, J. G. C.; Lopes, G. S.; Netto, F. A. D.; Teixeira, A. F. T. "High Efficiency Flex-Fuel Engines and the End of the 70\% Paradigm". SAE paper 2017-36-0162 (2017). 